\title{
Global Rsh-dependent transcription profile of Brucella suis during stringent response unravels adaptation to nutrient starvation and cross-talk with other stress responses
}

\author{
Nabil Hanna ${ }^{1,2,3}$, Safia Ouahrani-Bettache ${ }^{1,2,3}$, Kenneth L Drake ${ }^{4}$, L Garry Adams ${ }^{5}$, Stephan Köhler ${ }^{1,2,3^{*}+}$ \\ and Alessandra Occhialini ${ }^{1,2,3^{*}+}$
}

\begin{abstract}
Background: In the intracellular pathogen Brucella spp., the activation of the stringent response, a global regulatory network providing rapid adaptation to growth-affecting stress conditions such as nutrient deficiency, is essential for replication in the host. A single, bi-functional enzyme Rsh catalyzes synthesis and hydrolysis of the alarmone (p) ppGpp, responsible for differential gene expression under stringent conditions.

Results: cDNA microarray analysis allowed characterization of the transcriptional profiles of the B. suis 1330 wildtype and $\Delta r s h$ mutant in a minimal medium, partially mimicking the nutrient-poor intramacrophagic environment. A total of 379 genes (11.6\% of the genome) were differentially expressed in a rsh-dependent manner, of which 198 were up-, and 181 were down-regulated. The pleiotropic character of the response was confirmed, as the genes encoded an important number of transcriptional regulators, cell envelope proteins, stress factors, transport systems, and energy metabolism proteins. Virulence genes such as narG and sodC, respectively encoding respiratory nitrate reductase and superoxide dismutase, were under the positive control of (p)ppGpp, as well as expression of the cbb3-type cytochrome c oxidase, essential for chronic murine infection. Methionine was the only amino acid whose biosynthesis was absolutely dependent on stringent response in B. suis.

Conclusions: The study illustrated the complexity of the processes involved in adaptation to nutrient starvation, and contributed to a better understanding of the correlation between stringent response and Brucella virulence. Most interestingly, it clearly indicated (p)ppGpp-dependent cross-talk between at least three stress responses playing a central role in Brucella adaptation to the host: nutrient, oxidative, and low-oxygen stress.
\end{abstract}

Keywords: Brucella, Stringent response, Transcriptome, Virulence, Methionine biosynthesis, Low oxygen stress, Oxidative stress

\section{Background}

The Gram negative bacterial pathogen Brucella is the causative agent of brucellosis, a major zoonotic disease causing abortion and sterility in animals and "Malta fever" in humans. The latter is characterized by an undulant

\footnotetext{
* Correspondence: stephan.kohler@cpbs.cnrs.fr; alessandra.occhialini@cpbs. cnrs.fr

†Equal contributors

'Université Montpellier 1, Centre d'études d'agents Pathogènes et Biotechnologies pour la Santé (CPBS), Montpellier, France

${ }^{2}$ CNRS, UMR 5236, CPBS, Montpellier, France

Full list of author information is available at the end of the article
}

fever and septicemia which may be followed by a subacute or chronic infection [1]. The intracellular survival and replication of Brucella is considered the essential trait of virulence where the Brucella-containing phagosomes avoid bactericidal mechanisms by evading fusion with degradative lysosomes, a process which is mainly orchestrated by the type IV secretion system VirB [2,3]. During the infection, Brucella is able to survive and to adapt to nutrientpoor conditions like those encountered inside the Brucella-containing vacuole. A major bacterial strategy to cope with such conditions is the activation of the stringent response, a global regulatory network providing rapid

\section{Ciomed Central}


adaptation to a variety of growth-affecting stress conditions [4]. This rapid adaptation is mediated by the accumulation of an alarmone molecule called (p)ppGpp that binds to RNA polymerase, resulting in a large-scale downregulation of the translation apparatus [5]. The wellstudied stringent response is involved in the adaptation to amino acid starvation [6,7], but also to carbon or nitrogen [6,8-10], iron [11], and fatty acid starvation [12]. In Escherichia coli, the level of (p)ppGpp is regulated by the enzymes RelA that synthesizes the alarmone following activation by the presence of uncharged tRNAs, and SpoT, a bifunctional enzyme, able to synthesize and hydrolyse (p)ppGpp [6]. The majority of Gram-positive bacteria and the $\alpha$-Proteobacteria, to which belongs Brucella spp., however, possess a single, RelA-SpoT homologue named Rel or Rsh. RelA-SpoT homologues share both conserved (p)ppGpp synthase and hydrolase domains and were demonstrated to be bifunctional in Gram-positive bacteria and in $\alpha$-Proteobacteria at the examples of Sinorhizobium meliloti and Rhizobium etli [10,13-15].

Several studies demonstrated essentiality of the stringent response in many infectious processes. An active stringent response is required for the expression of pneumolysin toxin in Streptococcus pneumoniae [16], invasiveness and the expression of the type IV secretion system Dot/Icm in Legionella pneumophila [17], and mycobacterial longterm survival within macrophages [18] as well as persistence in the murine model [19]. In biofilms, which are related to many chronic infections, nutrient limitation results in a stringent response-dependent antibiotic tolerance and increased antioxydant defenses [20]. In symbiotic $\alpha$-Proteobacteria such as $S$. meliloti and $R$. etli, the stringent response controls bacterial physiology which is critical to the establishment of a successful symbiosis [15,21]. In the latter, (p)ppGpp-dependent genes have also been identified during active growth in early exponential phase [15].

In Brucella, the unique rsh gene encodes a protein of 751 amino acids, and homology analysis showed that the synthase and hydrolase residues were conserved, which suggests that Rsh is bifunctional. In a previous study, we demonstrated the role of $r s h$ in successful intracellular adaptation [22]. The rsh null mutant showed altered morphology, reduced survival in synthetic minimal medium, strong attenuation in cellular and murine models of infection, and lack of induction of virB expression [23]. A rsh mutant of Brucella abortus is also strongly attenuated in the macrophage model of infection and shows a higher sensitivity to $\mathrm{NO}$ - and acid $\mathrm{pH}$-mediated bacterial killing, resulting in a lower general stress resistance than the wild-type strain [24]. Such a wide-range regulation necessitates a global gene expression study to elucidate the role of (p)ppGpp in controlling the regulatory processes and networks implicated in the survival and adaptation of brucellae to various environmental conditions. In this study, we determined the transcription profiles of the wild-type and of a rsh mutant of Brucella suis, a Brucella species pathogenic for humans, after stringent response induction in a synthetic minimal medium, partially mimicking conditions encountered by the pathogen within the host cell. Transcription profiling allowed the identification of the global rsh-dependent regulatory network in this pathogenic $\alpha$-Proteobacterium, revealing, amongst others, stringent response control of methionine biosynthesis as well as of nitrate reductase, $\mathrm{Cu}, \mathrm{Zn}$ superoxide dismutase and $c b b 3$-type cytochrome c oxidase. Moreover, the large number of differentially regulated genes was consistent with the pleiotropic effect of the response.

\section{Results}

\section{Differential gene expression during stringent response in} B. suis

Expression profiles of $B$. suis 1330 wild-type and the $\Delta r s h$ mutant were generated using bacteria incubated for $4 \mathrm{~h}$ in minimal medium at $\mathrm{pH} 7.0$, conditions known to induce expression of rsh-regulated genes in Brucella spp. and necessitating the presence of Rsh for growth [23]. Viability of the rsh mutant was not affected during this incubation period (not shown). Prior to transcriptional analysis, the deletion of $r s h$ in the $\Delta r s h$ mutant was controlled and confirmed by PCR using primers flanking the mutated region. The whole-genome microarray transcriptional profiling yielded a signal for $r s h$ expression also in the $\Delta r s h$ mutant, as the sequence of the spotted 70-mer oligo specific for $r s h$ is located downstream of the deleted region. In addition, RT-qPCR showed that the transcription level of the neighboring gene $p y r E$ was not significantly affected, thus confirming that the $\Delta r s h$ mutation has no polar effect on transcription of genes located downstream.

Comparative transcriptional analysis between B. suis wild-type and the $\Delta r s h$ mutant revealed the Rshdependent differential regulation of 379 genes, which accounts for $11.6 \%$ of the genome. 198 of these genes (52\%) were up-regulated and 181 genes (48\%) were downregulated by Rsh (Figure 1, and Additional file 1: Table S1).

The differential expression varied between a 5.3-fold Rsh-dependent up-regulation of a gene coding for a protein of unknown function (BR0629; expressed as log2: 2.41), and an 8.4-fold Rsh-dependent down-regulation (ureB-1; expressed as $\log 2$ : -3.06). Differentially expressed genes were grouped into functional categories (Additional file 1: Table S1). Genes were relatively equally distributed over the different functional groups, except for a very strong representation of genes encoding proteins with unknown functions (32\%). It appeared, as expected, that in B. suis, Rsh controlled a variety of different metabolic 


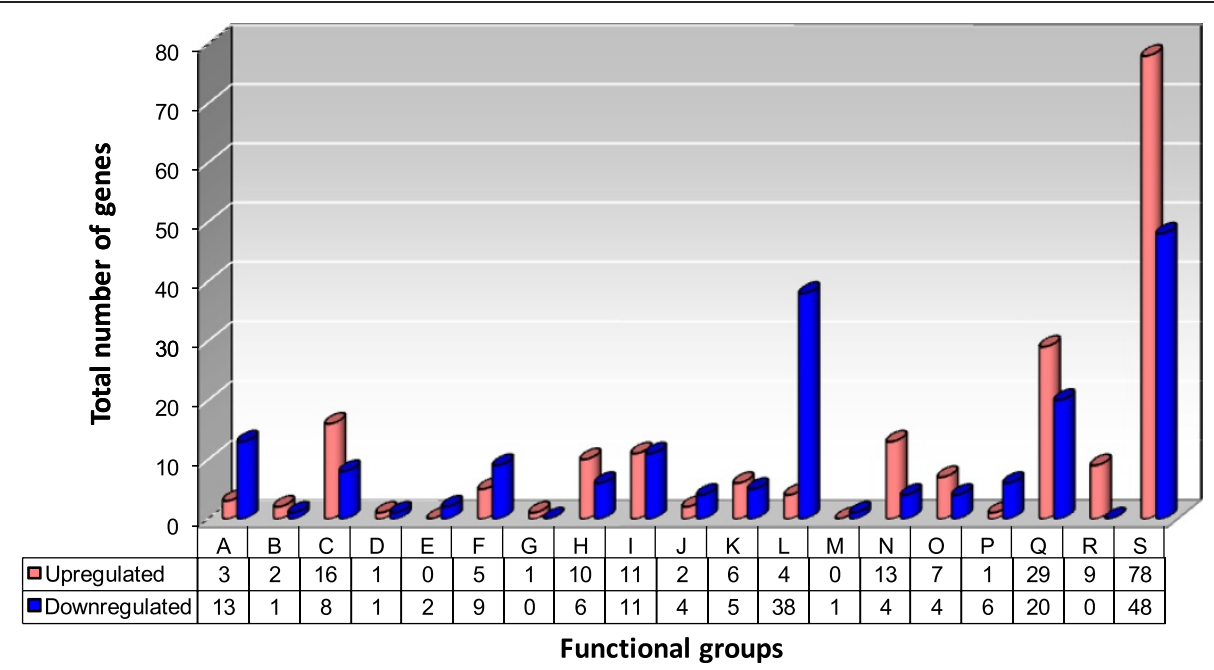

Figure 1 Stringent response-regulated genes of Brucella suis 1330 have been classified into 19 functional categories. A total of 379 genes were differentially regulated in minimal medium, representing $11.6 \%$ of the Brucella genome. "Up-" (red bars) and "Down-regulated" (blue bars) refers to the wild-type situation, in the presence of functional Rsh. A: Amino acid metabolism; B: Cell Division; C: Cell envelope; $\mathbf{D}$ : Central intermediary metabolism; E: Chemotaxis and motility; F: Cofactor and carrier biosynthesis; G: Detoxification; H: DNA/RNA metabolism; I: Energy metabolism; J: Fatty acid metabolism; K: Nitrogen metabolism; L: Protein metabolism; M: Protein modification and repair; N: Regulation; O: Stress and adaptation/chaperones/protein folding; P: Sugar metabolism; Q: Transport systems; R: Transposon function; S: Unknown function.

pathways through transcriptional regulation of a large number of genes. Consistent with the previously described link between the stringent response and production of $(\mathrm{p})$ ppGpp, a total of 120 of the differentially expressed genes were involved in amino acid, nucleic acid, energy, fatty acid, nitrogen, protein or sugar metabolism. $31 \%$ of these metabolism genes were up-regulated and 69\% were downregulated in the presence of a functional $r s h$ gene.

\section{Genes up-regulated during stringent response}

198 (52\%) of the differentially expressed genes identified in this study were positively regulated by Rsh, characterized by a significantly higher expression rate in the wildtype than in the $\Delta r s h$ strain (Additional file 1: Table S1). Among the up-regulated genes, only three (BR0793, BRA0338, BRA0340) were homologous to genes encoding enzymes involved in amino acid metabolism: BRA0338, homologous to genes encoding glutamate decarboxylase and possessing an authentic point mutation in B. suis, BRA0340, encoding a glutaminase catalyzing the formation of glutamate from glutamine, and BR0793 encoding O-acetylhomoserine sulfhydrylase, participating in the methionine biosynthesis pathway. Ten genes were implicated in DNA/RNA metabolism, including $\operatorname{himA}$ (BR0778) encoding the integration host factor (IHF) alpha subunit. As a transcriptional regulator, IHF binds to the promoter of the $\operatorname{vir} B$ operon, participating in control of its expression during the intracellular and vegetative growth in various media [25]. Twelve genes, including narG and narJ from the respiratory nitrate reductase operon, and $c c o N$ and $c c o P$ encoding $2 c b b_{3}$-type cytochrome $c$ oxidase subunits, were involved in energy metabolism. The $c b b_{3}$-type cytochrome $c$ oxidase is a high-oxygen-affinity terminal oxidase and hence allows brucellae to adapt to low oxygen tension. It was identified to be strongly induced under microaerobic conditions in vitro and essential for chronic, B. suis-mediated murine infection [26,27]. Six genes involved in nitrogen metabolism and belonging to the ure2-operon were up-regulated, as well as four genes classified as belonging to protein metabolism, and one gene involved in sugar metabolism. Two genes participating in fatty acid metabolism were also upregulated, BR1510 encoding an acyl-CoA hydrolase, and fadD (BR0289) which encodes an acyl-CoA synthase described to be required for the growth of Mycobacterium tuberculosis in a hepatocyte cell line and in mice $[28,29]$ and implicated in sulfolipid production and macrophage adhesion [30]. The gene $\operatorname{sod} C$, encoding a $\mathrm{Cu}, \mathrm{Zn}$ superoxide dismutase participating in detoxification of free oxygen radicals [31], was also up-regulated. In addition, we observed Rsh-dependent up-regulation of two ftsK genes encoding cell division proteins. This is consistent with the morphological abnormalities described in our and another previous study on $B$. abortus, where a high proportion of the bacteria were characterized by a branched or unusually swollen phenotype [23,24]. FtsK has been described to couple cell division with the segregation of the chromosome terminus [32].

The stringent response also positively affected stressrelated gene expression of a number of heat and cold shock genes and molecular chaperones (grpE, hdeA, csp, $d n a J, u s p$ ). Transcription of hdeA (BRA0341) was up- 
regulated in the presence of $r s h$, and in B. abortus, HdeA contributes to acid resistance but is not required for virulence in the Balb/c murine model [33]. Several of the genes up-regulated in a Rsh-dependent manner encode functions related to transcription, with the identification of twelve transcriptional regulators belonging to different families (GntR, RpiR, MerR, LysR, Ros/MucR). GntR5 has been identified as HutC, a transcriptional regulator that exerts two different roles, as it acts as a co-activator of transcription of the virB operon, and represses the hut genes implicated in the histidine utilization pathway [34]. The regulator MucR has been described as being involved in virulence of Brucella melitensis and B. abortus in macrophage and murine models of infection [35,36], in lipid A-core and cyclic- $\beta$-glucan synthesis in B. melitensis [37], and in the successful establishment of symbiosis in $S$. meliloti, including control of exopolysaccharide biosynthesis, necessary for biofilm formation [38,39].

Several other genes encoding factors associated with Brucella virulence have been identified as being regulated by (p)ppGpp, which is in agreement with observations made in other bacterial pathogens $[17,40,41]$. These genes, up-regulated in a Rsh-dependent manner and identified in independent virulence screens [42] (the latter as review) include those involved in cell envelope formation (omp19, $w b p L$, lpsA, amiC, $w b d A$ ), in DNA/RNA metabolism ( $m u t M$ and $p y r B$ ), in stress response (csp), in transport/secretion systems (virB5 and $d p p A$ ), and one gene encoding a protein of unknown function. The roles of the $c b b_{3}$-type cytochrome $c$ oxidase (encoded by the genes of the operon $c c o$ ) and of the $\mathrm{Cu}, \mathrm{Zn}$ superoxide dismutase (encoded by $\operatorname{sod} C)$ were described elsewhere [26,27]. Table 1 lists these
15 genes positively regulated by (p)ppGpp and participating in Brucella virulence.

\section{Genes down-regulated during stringent response}

In parallel, transcriptome analysis revealed 181 downregulated genes (Additional file 1: Table S1). The gene most strongly down-regulated in the presence of Rsh was ureB1 encoding the urease beta-subunit, involved in nitrogen metabolism and forming part of the ure-1 operon. The other four genes identified as belonging to the ure-1 operon (ureC, ureD1, ureE1, and ureG1) were also repressed. The hallmark of the stringent response is the (p) ppGpp-dependent down-regulation of transcription of the genes encoding ribosomal proteins. In fact, in our transcriptome analysis, all the genes encoding ribosomal proteins identified in this transcriptome $(n=29)$ were down-regulated. Among the genes coding for transcriptional regulators, we identified three genes (BR1187, BR1378 and BR0872) belonging to the MerR, AspB, and ExoR family, respectively, as being down-regulated, the latter being described as repressing exopolysaccharide production. Interestingly, two genes of the flagella clusters, identified as $f l a F$ and $f l i G$, were also affected. Flagella can be detected under certain culture conditions in Brucella, but their biological function remains yet unknown [43]. Fatty acid and glycerophospholipid biosynthesis were most likely reduced during stringent response, as we identified four genes involved in these processes being downregulated in the presence of Rsh. Similarly, metabolism of sugars and glycolysis were apparently diminished, in agreement with a general reduction of metabolic activities. We also observed the down-regulation of the gene

Table 1 Genes identified as being positively regulated by Rsh during stringent response, and previously described as essential for virulence of Brucella spp. in in vitro and/or in vivo models of infection

\begin{tabular}{|c|c|c|c|c|}
\hline B. suis Gene ID & B. melitensis Gene ID & Gene & Putative or assessed function & References \\
\hline BR0511 & BMEI1426 & $w b p l$ & O-chain biosynthesis & {$[35,42]$} \\
\hline BR0615 & BMEI1326 & $\operatorname{lps} A$ & Putative glycosyltransferase & {$[35,42]$} \\
\hline BR0915 & BMEI1056 & amic & Cell-wall hydrolysis & [42] \\
\hline BR0982 & BMEI0997 & $w b d A$ & O-chain biosynthesis & {$[35,42]$} \\
\hline BR1930 & BMEI0135 & omp19 & Lipoprotein & [42] \\
\hline BRA0703 & BMEII0581 & sodC & $\mathrm{Cu} / \mathrm{Zn}$ super oxide dismutase & {$[42,52]$} \\
\hline BR2183 & BMEl1946 & mutM & Repair from mutagenesis by alkylating agents & [42] \\
\hline BRA0599 & BMEII0670 & pyrB & Pyrimidines biosynthesis & [42] \\
\hline BR0363, BR0360 & BMEI1564, BMEI1566 & $C C O N, P$ & cytochrome $c$ oxidase, cbb3-type & {$[26,27]$} \\
\hline BR0569 & BMEI1364 & mucR & Transcriptional regulator & [35] \\
\hline BR1514 & BMEI0498 & $\operatorname{csp}$ & Cold shock protein & [35] \\
\hline BRA0065 & BMEII0029 & virB5 & Macromolecule secretion & [42] \\
\hline BRA1012 & BMEI0433 & $d p p A$ & Dipeptide uptake & [42] \\
\hline BR0049 & BMEl1894 & - & Conserved hypothetical protein & {$[35]$} \\
\hline
\end{tabular}

Genes belonging to same functional groups are listed together. 
encoding GlnE, responsible for adenylylation of glutamine synthetase (GS). Reduced adenylylation increases GS activity, and the synthetized glutamine plays a central role in the biosynthesis of amino acids, purines, and pyrimidines.

In addition, we found a wide range of genes encoding ORFs with unknown functions to be differentially regulated during stringent response.

\section{Validation of the microarray expression data by RT-qPCR analysis}

RT-qPCR was used to validate the expression trends of selected genes identified as being differentially expressed by microarray analysis. Using the same total RNA preparations as for the microarray hybridizations, expression of selected genes, representing the previously defined different functional groups, was analyzed by RT-qPCR. Gene BR1035 of unknown function was used as internal reference for normalization, as its expression rate was constant for both strains in the experiments. The expression ratios obtained from RT-qPCR and microarrays were plotted for comparison (Figure 2, and Additional file 2: Figure S1).

We investigated a total of 40 genes representing most of the previously defined functional groups. Using RT-
qPCR, thirty one $(78 \%)$ of the tested genes were found to be differentially expressed between wild-type and rsh-mutant, when applying a cutoff value of $\log 2(\mathrm{x})>$ 0.66 or $\log 2(1 / x)<-0.66$ (i.e. a plain fold change $>1.5)$, and each of these genes was regulated in the same direction (up or down), according to both RT-qPCR and the microarray study. Four other genes were identified as being regulated in the same direction (up or down) for both RT-qPCR and microarray analysis, but the rates of differential expression were not significant for RTqPCR. Up-or down-regulation opposite to the direction of regulation obtained by the microarray study was observed by RT-qPCR for the five remaining genes, out of the total of 40 . Therefore, the overall correlation between the expression levels obtained by microarrays and those obtained by RT-qPCR was good. Altogether, these results confirmed that $r$ sh-dependent differential gene expression evidenced by oligonucleotide microarray analysis could be reproduced by RT-qPCR.

Nitrate reductase, $c b b 3$-type cytochrome $c$ oxidase, and $\mathrm{Cu}, \mathrm{Zn}$ superoxide dismutase (SOD) of B. suis are under the positive control of (p)ppGpp.

Induction of the nar operon by (p)ppGpp, as observed by microarray analysis and RT-qPCR (Additional files 1: Table

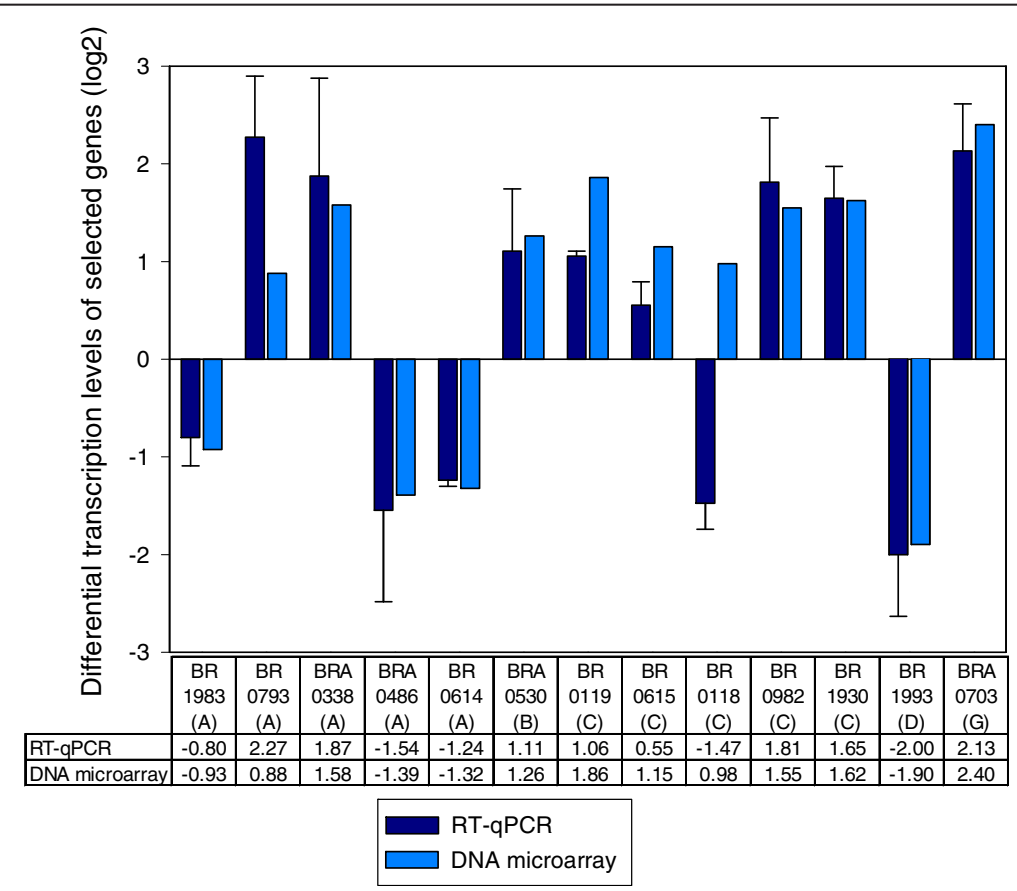

Figure 2 Comparison of microarray analysis to real-time PCR revealed $78 \%$ of true positives. Log2-values of fold-changes of differentially expressed genes under stringent conditions are shown for normalized microarray data and RT-qPCR of 13 ORFs (out of 40 total; see also Additional file 2: Figure S1) representing the different functional groups: A- Amino acid metabolism; B- Cell Division; C-Cell envelope; D- Central intermediary metabolism; G- Detoxification. Expression of 78\% of all chosen ORFs (including those presented in Additional file 2: Figure S1) was consistent for both methods, with a $\log 2(x)>0.66$ or $\log 2(1 / x)<-0.66$ (representing a plain fold-change $>1.5$ ). For the remaining $22 \%$, the fold-change was inferior to $\log 2(x)=0.66$ or superior to $\log 2(1 / x)=-0.66$ (representing a fold change $<1.5$ ) or not consistent with microarray analysis. Relative differences of transcription levels between B. suis wild-type and the $\Delta$ rsh mutant were determined as $2^{-\Delta \Delta C t}$ values, as described in Methods. 
S1 and 2: Figure S1), was confirmed biochemically by measurement of the enzymatic activity of the nitrate reductase operon. After a $4 \mathrm{~h}$-induction of the bacteria in GMM, the $\mathrm{NO}_{2}^{-}$production was measured in the bacterial culture supernatants. Consistent with the microarray and RT-qPCR results, significant production of $\mathrm{NO}_{2}{ }^{-}$was observed in the $B$. suis wild-type strain with a mean nitrite concentration of $698.5 \pm 6.5 \mu \mathrm{M}$, as compared to its $\Delta r s h$ isogenic mutant with a strongly reduced nitrite concentration of only $40.2 \pm 6.4 \mu \mathrm{M}$. A $\Delta$ narG mutant, deficient in nitrite production, was used as a negative control [44]. In the same functional group of energy metabolism, two genes encoding subunits of the cbb3-type cytochrome $c$ oxidase were also induced (Additional files 1: Table S1 and 2: Figure S1).

Both microarray and RT-qPCR results also revealed that induction of $\operatorname{sod} C$, encoding $\mathrm{Cu}, \mathrm{Zn}$ superoxide dismutase, was rsh-dependent (Figure 2, Additional file 1: Table S1). Production of exogenous $\mathrm{O}_{2}{ }^{-}$was artificially induced by the xanthine oxydase reaction, where xanthine is converted to urate, generating $\mathrm{O}_{2}-$. The number of surviving bacteria in the cell suspension was determined at specific time points thereafter. Despite lower initial survival of brucellae in the preculture due to pleiotropic effects of rsh mutation, there was a clear correlation between $r s h$ expression and resistance to $\mathrm{O}_{2}^{-}$radicals: the net difference in survival between the wild-type and the $\Delta r s h$ strain was 50 -fold at $30 \mathrm{~min}$ and 500-fold at $1 \mathrm{~h}$ (Figure 3). The higher sensitivity of the rsh mutant to $\mathrm{O}_{2}^{-}$was completely abolished following complementation with the intact gene and survival was not significantly different from that of the wild-type strain (Figure 3).

\section{Growth of a rsh null mutant in minimal medium requires methionine, present in the Brucella-containing vacuole of macrophages}

Lack of stringent response in a $\Delta r s h$ mutant resulted in lack of growth in GMM, which was restored in the complemented strain [23]. In order to characterize the nutritional requirements of a $\Delta r s h$ mutant under these growth conditions, we analyzed the amino acid requirements of the rsh null mutant in GMM. Each of the 20 culture tubes per $B$. suis wild-type and $\Delta r s h$ strain, respectively, contained all but one of the 20 amino acids. Control cultures in medium lacking all amino acids and in medium containing all 20 amino acids (not shown), as well as a $\Delta m e t H$ mutant and its complemented form, were also included. The $\Delta m e t H$ mutant (BR0188) was unable to synthesize 5-methyltetrahydrofolate-homocysteine methyltransferase, the last enzyme in the methionine biosynthesis pathway, transforming L-homocysteine into L-methionine. Results showed that the $r s h$ mutant did not grow in medium lacking only methionine (Figure 4). As expected, the $\Delta m e t H$ mutant behaved the same way.

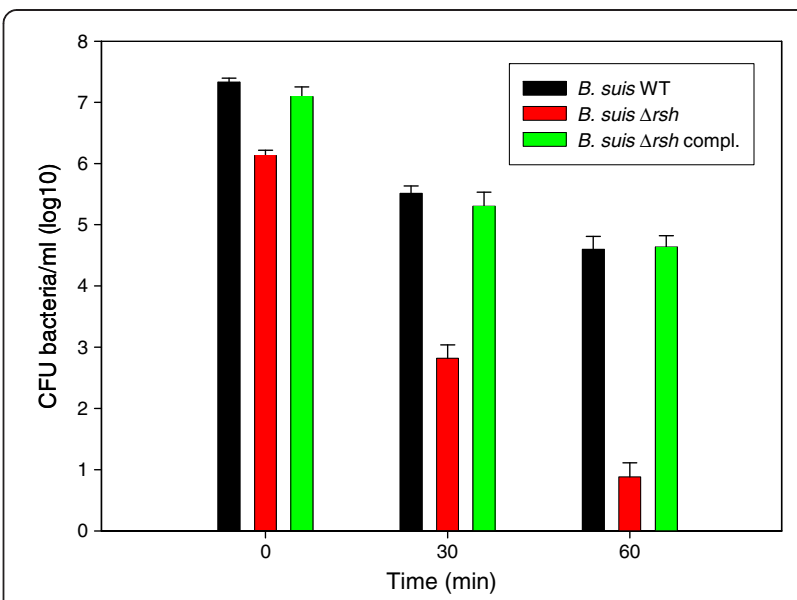

Figure 3 The $\Delta r$ sh mutant is highly sensitive to exposure to $\mathbf{O}_{2}{ }^{-}$. Determination of the concentrations of viable $B$. suis wild-type (black bars), $\Delta$ rsh mutant (red bars), and complemented rsh mutant (green bars) following 30 and 60 min of exposure to $\mathrm{O}_{2}{ }^{-}$generated by the xanthine oxidase reaction, as described in Methods.

Growth was restored upon the addition of methionine, indicating that only the methionine biosynthesis pathway was affected in the $\Delta r s h$ mutant able to synthesize all other amino acids under nutrient starvation (Figure 4). Addition of exogenous methionine to the wild-type and to the complemented $\Delta m e t H$ mutant favoured earlier growth of the strains as compared to growth rates in GMM lacking methionine.

In order to determine if the lack of capacity to synthesize methionine could also explain the inability of the $\Delta r s h$ mutant to replicate in the macrophage model of infection [22], the above-described metH mutant was used in the infection experiments. Interestingly, the $\Delta m e t H$ mutant was not attenuated in the J774 murine macrophage model of infection (Figure 5), leading to the conclusion that this amino acid was available in the Brucella-containing vacuoles and that the intracellular attenuation of the rsh mutant was not due to amino acid starvation.

Microarrays and RT-qPCR data revealed that metH was not regulated in a (p)ppGpp-dependent manner under stringent conditions, in contrast to metA (BRA0486) which was down-regulated and to the gene BR0793 which was up-regulated in the presence of Rsh (Figure 2, Additional file 1: Table S1). Mutants respectively carrying the inactivated genes metA, metZ, or BR0793 encoding $\mathrm{O}$-acetylhomoserine sulfhydrylase, were characterized by reduced growth in GMM (not shown). This result was consistent with the known general methionine biosynthesis pathway composed of two parallel branches, one including met $A$ and met $Z$ and the other BR0793. RT-qPCR was therefore employed to systematically assess an eventual link between $r s h$ and the expression of genes located 


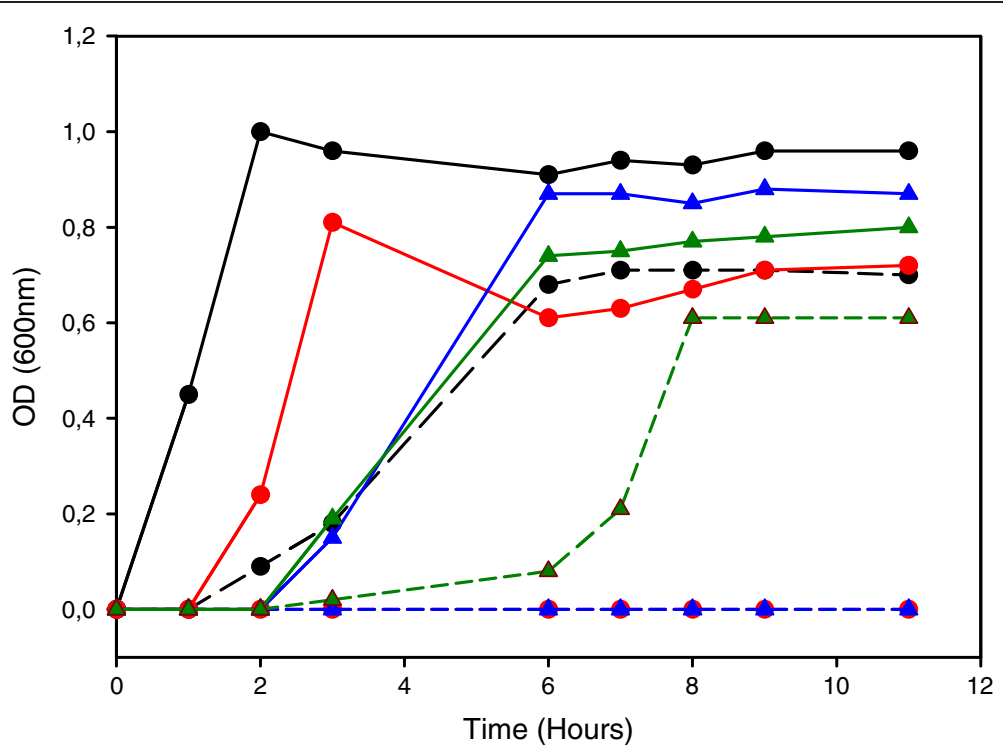

\begin{tabular}{ll} 
& B. suis WT + methionine \\
& B. suis WT \\
- & B. suis $\Delta r s h+$ methionine \\
- & B. suis $\Delta r s h$ \\
- & B. suis $\Delta m e t H+$ methionine \\
$--1-$ & B. suis $\Delta m e t H$ \\
\hline- & B. suis $\Delta m e t H+$ pBBR1MCS-metH + methionine
\end{tabular}

Figure 4 Growth of the $\Delta r$ sh mutant in minimal medium requires addition of methionine only. B. suis 1330 wild-type (black), B. suis strains $\Delta$ rsh (red), $\Delta$ metH (blue) and $\Delta$ metH complemented with the metH gene on plasmid pBBR1-MCS (green), were grown in TS medium overnight, washed twice, and diluted 1/500 in GMM in the absence (dashed lines) or presence (solid lines) of methionine. Bacterial growth was measured at $\lambda 600 \mathrm{~nm}$. Both $\Delta \mathrm{rsh}$ and $\Delta$ metH mutants were unable to grow in the absence of methionine and both graphs superpose as a "base line". +met: addition of exogenous methionine; +pBBR1-MCS-metH: complementation plasmid for $\Delta$ metH mutant.

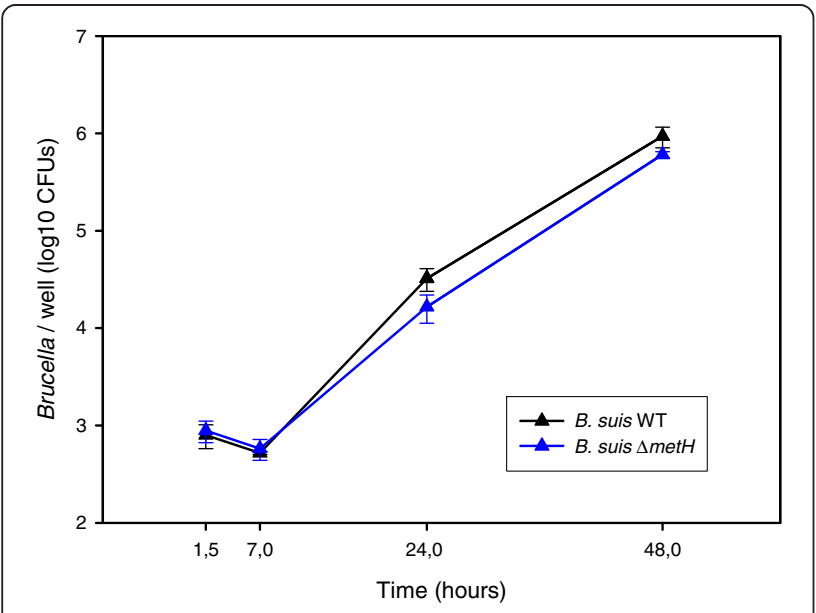

Figure 5 Intracellular growth of $B$. suis does not require bacterial methionine synthesis. Murine $\mathrm{J} 774$ macrophage-like cells were infected with B. suis wild-type (black) and the $\Delta$ metH mutant (blue). The experiments were performed three times in triplicate each. Data are presented as means \pm standard deviations of one representative experiment. further "upstream" on the methionine biosynthesis pathway (Figure 6).

The transcripts encoding aspartate kinase (BR1871) with $\log 2(\mathrm{x})$ of the differential expression ratio wild-type $/ r s h=$ $0.89 \pm 0.15$, and homoserine dehydrogenase (hom; BR1274) with $\log 2(\mathrm{x})$ of the differential expression ratio wild-type Irsh $=0.83 \pm 0.51$ were found to be significantly less abundant in the $r s h$ mutant than in the wild-type strain. These data indicated that in addition to positively regulating the transcription levels of O-acetylhomoserine sulfhydrylase (BR0793), Rsh was also involved in the positive regulation of the two genes BR1274 and BR1871 encoding proteins further upstream in the central part of the methionine biosynthesis pathway, between the L-aspartate and the L-homoserine intermediate product (Figure 6).

\section{Discussion}

The stringent response reflects the adaptation of a bacterium to nutrient stress via a complex differential gene expression pattern, affecting a large number of structural and regulatory target genes and resulting in a pleiotropic phenotype. In an earlier study, some of us showed that 


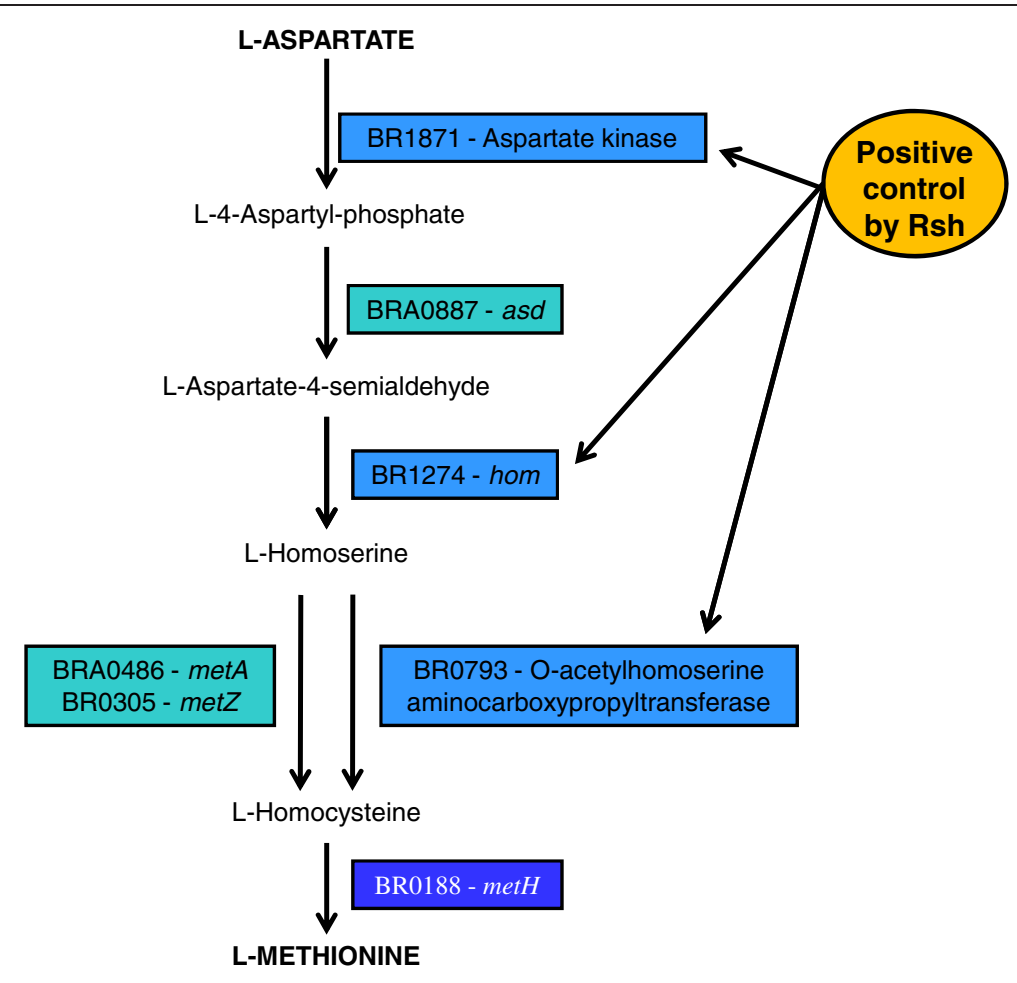

Figure 6 Three genes of the methionine biosynthesis pathway were positively regulated by (p)ppGpp in B. suis. The different genes encoding the enzymes involved in the pathway from L-Aspartate to L-Methionine are represented. Gene BR0793 was identified by microarray analysis and RT-qPCR, genes BR1871 and BR1274 by RT-qPCR.

rsh deletion mutants were characterized by altered morphology, lack of expression of virB, and reduced survival in cellular and murine models of infection [23]. In this study, we investigated the global expression profile of the stringent response using a DNA microarray approach with the aim to characterize the (p)ppGppdependent regulatory network, and we also focused on methionine biosynthesis, the sole amino acid whose biosynthesis pathway was controlled by stringent response in B. suis.

A comparison of the wild-type and rsh mutant transcriptomes showed that approximately $12 \%$ of the B. suis genome were under the control of Rsh, of which $52 \%$ were up-regulated and $48 \%$ were down-regulated. The differentially transcribed genes were classified into 19 functional categories.

A key element in the establishment of Brucella infection is the ability of the bacterium to resist to acid $\mathrm{pH}$ and nutrient deprivation within the macrophage host cells, at least in the early phase of infection. Both signals are essential for a strong induction of the T4SS in B. suis, although RNA blot experiments with a virB5-probe reveal some virB-expression in minimal medium at $\mathrm{pH} 7$ [45], corresponding to our experimental conditions in this transcriptome study. Our transcriptome study showed that virB-expression was Rsh-dependent, which is in accordance with previous work of some of us [23]. On a fine-tune level, the gene encoding the alpha-subunit of the Integration Host Factor (IHF) and hutC, which both control transcription of the virB operon via specific promoter binding sites, were also up-regulated under nutrient stress conditions. In $E$. coli, it has been described that expression of IHF is induced under stringent response conditions and in early-stationary phase $[46,47]$. The Rsh-dependent up-regulation of IHF-expression in Brucella confirmed the regulation pathway previously suggested: Brucella senses nutrient starvation via Rsh, resulting in (p)ppGpp production, which will then increase transcription of IHF, affecting the activity of the Brucella virB promoter [48]. However, the fact that overexpression of the virB operon in a B. suis $\Delta r s h$ background did not restore the parental phenotype by itself (data not shown) is an additional indication that the stringent response has a pleiotropic effect on virulence factor expression. Among transcriptional regulators participating in Brucella virulence, expression of MucR was shown to be Rsh-dependent. Studies on a mucR-mutant of B. melitensis suggest that MucR regulates genes involved in nitrogen metabolism and stress response [49], as well as in lipid A-core and cyclic- $\beta$ -glucan synthesis of this pathogen [37]. In this context it is important to mention that recent work on the 
transcriptome analysis of stringent response in the $\alpha$ proteobacterium and plant symbiont $R$. etli reported the observation that Rsh positively controls expression of key regulators for survival during heat and oxidative stress [15]. Remarkably, about 6\% of the (p)ppGpp-regulated genes in B. suis are transcriptional regulators of, most-often, uncharacterized function.

Several consecutive genes, potentially involved in resistance to acid $\mathrm{pH}$, were also induced by Rsh: genes encoding the glutamate decarboxylase A (BRA0338), the glutaminase (BRA0340), and hdeA (BRA0341). Glutamate decarboxylase, which is involved in resistance of Brucella microti to $\mathrm{pH} 2.5$ [50] is not functional in B. suis. This overexpression could be the remnant of a function that has been lost during the evolution of Brucella. However, this gene potentially forms an operon with hdeA (unpublished results), which plays a role in the resistance to acid stress in B. abortus [33]. These results suggest that Rsh may prepare the bacteria to respond to a possible acid stress subsequent to nutrient deficiency.

Experimental evidence indicates that production of reactive oxygen intermediates (ROIs) represents one of the primary antimicrobial mechanisms, and ROI formation has been described during macrophage infection by Brucella [51]. Among the genes positively regulated by Rsh that contribute to the virulence of Brucella, we identified sodC encoding the $\mathrm{Cu}-\mathrm{Zn}$ superoxide dismutase. A sodC mutant of $B$. abortus was more sensitive to killing by $\mathrm{O}_{2}^{-}$ than the wild-type, and exhibited an increased susceptibility to killing in cultured macrophages and in a murine model of infection [52]. We suggest that the lack of upregulation of this protective gene might participate in the attenuation previously described for the $\Delta r s h$ mutants of Brucella [22,23]. In addition, it has been reported recently for biofilm-forming $P$. aeruginosa that an active stringent response increased not only antibiotic tolerance, but also antioxydant defenses by increasing production of active catalase and SOD against endogenous oxydant production [20]. This indicated at least a partial conservation of stringent response-dependent adaptation strategies of different bacterial pathogens to various stress conditions encountered during chronic infection or biofilm formation.

One of the hallmarks of stringent response is the down-regulation of protein synthesis, together with induction of amino acid biosynthesis pathways. Based on the transcriptome results obtained for the well-studied stringent response of E. coli $[7,53]$ and on earlier reports [54], a major event of the stringent response consists in the repression of the translation apparatus, including ribosomal proteins. As expected, the transcriptome data of our study clearly demonstrated that the regulation of the translation apparatus is (p)ppGpp-dependent, as we identified 29 genes coding for ribosomal proteins that were down-regulated. The microarrays used in this study lack the genes of the rRNA operons of Brucella, explaining why these genes were not also identified as being down-regulated in the wild-type strain during stringent response. Regarding induction of amino acid biosynthesis pathways, it has been described that these pathways differ, depending on the bacterial species studied. In E. coli, the stringent response positively controls the biosynthesis of the branched-chain amino acids, glutamine/glutamate, histidine, lysine, methionine and threonine [54]. In B. subtilis, proteome and transcriptome analysis has shown induction of enzymes involved in branched-chain amino acid biosynthesis during stringent response [55]. The assessment of the amino acid biosynthesis pathways positively regulated by Rsh during the stringent response in $B$. suis revealed that only methionine biosynthesis was controlled by (p)ppGpp. As we previously put forward the hypothesis of a nutrient-poor environment during macrophage infection, based on the observation of the attenuation of several mutants affected in amino acid and nucleotide biosynthesis pathways $[22,56]$, we verified the possibility that Rsh-dependent methionine synthesis might be crucial during infection. We therefore constructed a $\Delta m e t H$ allelic exchange mutant of $B$. suis, which was auxotrophic. Intracellular growth of the $\Delta m e t H$ mutant, however, was not impaired, indicating that the lack of methionine biosynthesis in the $\Delta r s h$ mutant did not contribute to its attenuation and that methionine was available in the Brucella-containing vacuole. Our results are in contrast to those described by Lestrate et al. [57], who observed attenuation of a $B$. melitensis metH transposon mutant in vitro and in vivo, but, surprisingly, in the absence of any auxotrophic phenotype in minimal medium. In addition, genome sequencing of $B$. melitensis has since revealed that a gene encoding an alternative enzyme functionally replacing $\mathrm{MetH}$ is not present [58]. Interestingly, in the $\alpha$-proteobacterium and plant symbiont $R$. etli, (p)ppGpp-dependent upregulation of any amino acid biosynthesis pathways during stationary phase could not be evidenced. Rather, amino acid biosynthesis was down-regulated in a (p)ppGpp-independent manner under these growth conditions [15]. It therefore appears that induction of amino acid biosynthesis during stringent response is not a key feature in $\alpha$-proteobacteria.

The nar operon, which encodes the respiratory nitrate reductase in Brucella, was also induced under stringent conditions, as evidenced by the microarray analysis and by dosage of the nitrites produced by the nitrate reductase. Nar-induction was shown by the Rsh-dependent, positive control of the genes narG, narJ, and narK, involved in the first step of denitrification consisting in the reduction of nitrate to nitrite, and in nitrite extrusion towards the periplasm $[59,60]$. This denitrification pathway may allow Brucella to survive under low oxygen tension, using nitrogen oxides as terminal electron acceptors 
[61]. Denitrification can also be used by brucellae to detoxify NO produced by activated murine macrophages during infection, and part of this denitrification island is important for virulence of $B$. suis in vivo [44]. Recent proteomic and gene fusion studies with $B$. suis evidenced the induction of the nar operon under microaerobic conditions [61]. In E. coli, expression of the narGHJI operon is induced by low oxygen tension and by the presence of nitrate [62], which is imported by NarK, also responsible for nitrite export [63]. One might speculate that our observations made in GMM broth were due to low-oxygen exposure of the strains, but this appears unlikely as pre-cultures were diluted in minimal medium under vigorous shaking for 4 hours. In $M$. tuberculosis, oxygen concentration-independent expression of nar has been described [64], and nitrate reductase component genes narH and narI have been identified as being under the positive control of $\mathrm{Rel}_{\mathrm{Mtb}}$ (Rsh) under comparable nutrient starvation culture conditions [19]. It is therefore conceivable that the Brucella nitrate reductase is expressed in a stringent response-dependent manner under aerobic conditions, and further induced under hypoxia. In analogy to the observations made for the nar-operon, genes encoding cbb3-type cytochrome $c$ oxidase were also observed being under the positive control of Rsh in B. suis, despite normal oxygenation. We hypothesize that stringent response, mediating adaptation of the pathogen to nutrient stress, therefore also represents a first step of potential adaptation to successive reduction of oxygen concentrations encountered by the pathogen in the host cells, the target organs and granulomes or abcesses.

The gene $\operatorname{sod} C$, encoding $\mathrm{Cu}, \mathrm{Zn}$ superoxide dismutase, was also positively regulated by the product of Rsh. The mutant was significantly more sensitive to $\mathrm{O}_{2}^{-}$radicals then the wild-type in vitro, already at short times of treatment. It has been described previously that a $\operatorname{sod} C$ mutant of B. abortus exhibited much greater susceptibility to killing by $\mathrm{O}_{2}^{-}$than the parental strain [52]. The same mutant was also much more sensitive to killing in cultured macrophages, as well as in the murine model of in vivo infection, due to its inability to detoxify the $\mathrm{O}_{2}{ }^{-}$generated by the respiratory burst of the phagocytes [52]. In addition to the previous observation of some of us that $\operatorname{vir} B$ expression is Rsh-dependent [23], we therefore have now validated by a biological survival assay a second Brucella gene product whose activity was necessary for intramacrophagic and intramurine replication and whose expression was controlled by Rsh during starvation. In B. suis, stringent response therefore also participated in protection from oxidative stress. A similar observation has been reported lately for Pseudomonas aeruginosa, where stringent response mediates increase of antioxidant defenses [20].

Interestingly, both urease operons of B. suis were regulated during stringent response in GMM: The ure-1 operon, responsible for the urease activity observed in most species $[65,66]$, was less expressed in the (p)ppGppproducing wild-type strain than in the mutant, whereas ure-2 was more expressed under these conditions. In rich broth, i.e. under non-stringent conditions, urease activity, correlating with expression, has been described to be at its maximum in the absence of ammonium chloride, and enzymatic activity decreases with increasing ammonium concentrations [66]. Interestingly, a similar negative regulation of urease expression during stringent response has been described in Corynebacterium glutamicum [67]. The functions of the ure-2 cluster have been unraveled only recently: it is composed of genes encoding a urea and a nickel transport system within a single operon [68]. Our results are in agreement with those published by Rossetti et al., comparing the transcriptional profiles of $B$. abortus under logarithmic and stationary growth phase conditions: the ure-2 operon is induced during stationary phase, known to be triggered by stringent response [69].

The observation that flaF and fliG, belonging to flagellar loci I and loci III, respectively, were down-regulated, suggested that the flagellar apparatus of Brucella was repressed under stringent conditions. This result is in agreement with the $E$. coli transcription profile of the stringent response, where the expression of the $f l h D C$ flagella master regulator is rapidly down-regulated [70]. Hence, bacteria appear to shut down transcription of the flagellar cascade under starvation. This strategy makes physiological sense, as it would avoid the expending scarce energy resources for one of the bacteria's largest macromolecular complexes. In brucellae, the biological function of the flagellar components has not been determined yet, especially in the context of host cell infection. Very recently, down-regulation of flagellar genes expression by the transcriptional regulator MucR has been described in B. melitensis [37]. Our observation that MucR is positively regulated during stringent response in B. suis, whereas genes encoding the flagellar apparatus are down-regulated under the same conditions, indicates that such a link also exists in B. suis and, more generally, that (p)ppGpp is located high up in the hierarchy of gene regulation in Brucella spp.

Altogether, the transcription analysis of the stringent response in the facultatively intracellular pathogen B. suis confirmed the pleiotropic character of the (p) ppGpp-mediated adaptation to poor nutrient conditions. Several of the genes identified as being under (p)ppGpp control have also been described previously as being essential for the virulence of the pathogen [42], establishing a link between stringent response and virulence. Among these, five genes encoded proteins involved in cell envelope biosynthesis, of which four are essential for intramacrophagic replication of Brucella [42]. In addition, four outer membrane proteins (Omps) 
encoded by the genes BR0119, BR0971 (both putative Omps), BRA0423 (“Omp31-2"), and BR1622 (“Omp311 "), all under the positive control of (p)ppGpp during stringent response, have also been identified previously as being up-regulated in intramacrophagic $B$. suis at $48 \mathrm{~h}$ post infection [71]. At this rather late stage of intracellular infection, B. suis shows a high level of replication, and these four genes/proteins were described as being up-regulated in both studies, indicating the potential importance of these Omps throughout the various stages of intramacrophagic infection.

Last not least, the function of $33 \%$ of the genes encoding Rsh-dependent transcripts remains unknown. This illustrates the complexity of the processes involved in adaptation to nutrient starvation while bearing in mind that knowledge of a substantial part of the Brucella genome is still limited. In this context, it is also worthwhile to mention that in $E$. coli, stringent response induces the alternative, stationary-phase sigma factor RpoS $[7,53]$. In brucellae and other $\alpha$-proteobacterial species, however, a functional analogue of RpoS was unknown. Only very recently, an intact general stress response system (GSR), including genes encoding the regulator $p h y R$ and the alternative sigma factor $r p o E 1$, has been described for $B$. abortus [72]. The transcriptome analysis of the stringent response in $B$. suis described here did not give any indication that stringent response might directly affect expression of these two GSR-related genes. Either stringent response controls another, yet uncharacterized alternative sigma factor in Brucella, or binding of $(\mathrm{p})$ ppGpp to the RNA polymerase core affects competition between sigma factors in favor of an alternative sigma factor, which could then be RpoE1, increasing specific expression of stress-related genes.

\section{Conclusions}

Rsh, the enzyme controlling stringent response by the synthesis or hydrolysis of (p)ppGpp, affects expression of more than $10 \%$ of the genes of B. suis under nutrient starvation conditions. (p)ppGpp, as a regulator of gene expression, is thereby located high up in the hierarchy of gene regulation in Brucella spp., as we identified 17 transcriptional regulators under the control of Rsh. Expression of $\operatorname{vir} B$, the secretion system which plays a central role in Brucella virulence, is controlled by two transcriptional regulators which have been shown to be Rsh-dependent. Our novel data from the first stringent response transcriptome analysis of an $\alpha$-proteobacterial pathogen confirm that expression of additional virulence genes is also controlled by Rsh, as 14 other genes previously identified as essential for Brucella virulence are up-regulated by Rsh under nutrient starvation. This fact emphasizes the importance of stringent response in adaptation of this pathogen to the host, and yields additional explanation for our previous observations that Rsh is essential for intramacrophagic and intramurine replication.

In contrast to the work on stringent response published for other bacteria, where the biosynthesis pathways of several amino acids, respectively, are under positive (p)ppGpp control, only methionine biosynthesis is concerned in B. suis. As this amino acid is obviously not lacking in the Brucella-containing vacuole of the macrophage, we conclude that stringent response, triggered by nutrient starvation in this compartment, is crucial for the induction of a set of virulence genes, but not for the induction of the biosynthesis pathways needed to provide the lacking amino acids.

The transcriptome analysis of the stringent response in $B$. suis lead to the observation that the rsh mutant had a lower general stress resistance than the wild-type strain, allowing the hypothesis that stringent response and adaptation to nutrient stress may in fact trigger cross-talk with other general stress responses in Brucella, thereby preparing the pathogen to different stress conditions possibly encountered simultaneously or soon after. In the life cycle of $B$. suis within the host, starvation inside the macrophage cell may be the first major stress encountered. According to the transcriptome data discussed above, such cross-talk may take place between at least three stress responses playing a central role in Brucella adaptation to host: nutrient stress, oxidative stress and low-oxygen stress.

\section{Methods}

\section{Bacterial strains and media}

The Brucella reference strains used in this study were B. suis 1330 (ATCC 23444) and B. melitensis $16 \mathrm{M}$ (ATCC 23456). Ultra-competent $E$. coli DH5 $\alpha$ (Invitrogen) were used for cloning and plasmid production. Brucella and E. coli strains were grown in Tryptic Soy (TS) and Luria Bertani (LB) broth (Invitrogen, Carlsbad, CA, U.S.A.), respectively. For strains carrying resistance genes, kanamycin, ampicillin, and chloramphenicol were used at a final concentration of $50 \mu \mathrm{g} / \mathrm{ml}$ each. B. suis stringent response assays were performed as follows: a stationaryphase overnight culture obtained in TS was washed once in phosphate-buffered saline (PBS) prior to a 1:5 dilution in Gerhardt's Modified Minimal Medium (GMM) adjusted to $\mathrm{pH} 7.0$ [73], followed by incubation at $37^{\circ} \mathrm{C}$ with shaking for $4 \mathrm{~h}$. Concentrations of live bacteria $\mathrm{ml}^{-1}$ were determined prior and after induction by CFU counting after plating of serial dilutions onto TS agar, revealing starting concentrations of approximately $10^{9}$ viable bacteria $\mathrm{ml}^{-1}$ for both strains, and almost identical concentrations at the end of the experiment. Under these conditions, both strains remained fully viable but did not start active growth. 


\section{Growth assays}

For the identification of amino acids essential for $\Delta r s h$ growth in GMM, B. suis cultures were grown overnight at $37^{\circ} \mathrm{C}$ in TS broth. Bacteria were collected by centrifugation at 13,000 rpm for $5 \mathrm{~min}$, washed twice with $9 \%$ $\mathrm{NaCl}$, diluted 1:500 and used to inoculate twenty $15-\mathrm{mL}$ tubes containing $3 \mathrm{~mL}$ of GMM, where glutamate was replaced by ammonium sulfate, and all natural amino acids added at a concentration of $1 \mathrm{mM}$ each (Sigma), except one. The method was systematically applied to each of the 20 amino acids.

\section{Isolation and labeling of $B$. suis genomic DNA}

Genomic DNA was isolated from B. suis culture using Qiagen DNeasy blood and tissue kit and labeled by direct incorporation of Cy-5-dCTP fluorescent dye (Amersham) using the BioPrime DNA labeling system kit (Invitrogen) that contains random primers (octamers) and Klenow fragment. For a $50-\mu \mathrm{L}$ reaction mixture, $2 \mu \mathrm{g}$ of genomic DNA template in $23 \mu \mathrm{L}$ of sterile water were heated at $95^{\circ} \mathrm{C}$ for $10 \mathrm{~min}$, combined with $20 \mu \mathrm{l}$ of 2.5X random primers solution, heated again at $95^{\circ} \mathrm{C}$ for $5 \mathrm{~min}$, and chilled on ice. Remaining components were added to the following final concentrations: $0.12 \mathrm{mM}$ dATP, dGTP, and dTTP; $0.06 \mathrm{mM} \mathrm{dCTP;} 0.02 \mathrm{mM} \mathrm{Cy5-}$ dCTP; 1 mM Tris-HCl (pH 8.0); 0.1 mM EDTA; and 40 units of Klenow fragment. The solution was incubated at $37^{\circ} \mathrm{C}$ for $2 \mathrm{~h}$ before the reaction was stopped by adding EDTA ( $\mathrm{pH} 8.0$ ) to a final concentration of $45 \mathrm{mM}$. The fluorescence-labeled DNA was purified using the CyScribe GFX purification kit (Amersham Biosciences) and eluted in $1 \mathrm{mM}$ Tris $\mathrm{pH} 8.0$ and kept in the dark at $4^{\circ} \mathrm{C}$.

\section{Isolation of total RNA from $B$. suis}

Expression profiles of $B$. suis 1330 wild-type and the $\Delta r s h$ mutant were generated using $9 \mathrm{~mL}$ of bacteria incubated in GMM containing ammonium sulfate instead of glutamate, to ensure total amino acid starvation, at $\mathrm{pH} 7.0$ for $4 \mathrm{~h}$, conditions that are known to induce expression of $r s h$-regulated genes [23]. For each strain, four independent RNA preparations from four independent cultures were used. RNA extraction was performed with the RNeasy mini kit from Qiagen according to the manufacturer's instructions, with a modified lysis step.

Briefly, after addition of ethanol/phenol solution (9:1) to the cultures, the bacteria were recovered by centrifugation. The bacterial pellet was suspended in TE bufferlysozyme solution (Invitrogen). After $5 \mathrm{~min}$ of incubation, the lysate was mixed with $10 \%$ SDS and proteinase $\mathrm{K}$, and incubated for $10 \mathrm{~min}$ at $25^{\circ} \mathrm{C}$. Buffer RLT with beta-mercaptoethanol was added to the sample followed by centrifugation. The supernatant containing the RNA was recovered and transferred to RNeasy mini spin column. RNA samples were treated with RNAse-free DNase I (Ambion) according to the manufacturer's instructions. RNA concentration was determined at $\lambda$ $260 \mathrm{~nm}$ using the NanoDrop ND-1000, and quality was evaluated using a Nano-Chip on an Agilent 2100 Bioanalyzer.

\section{Microarray construction}

The pattern of the whole-genome oligo arrays was based on the sequenced genome of $B$. melitensis. The 70-base nucleotides representing 3,227 ORFs plus unique sequences from $B$. abortus and B. suis were designed by Sigma Genosys [69]. rRNAs-genes were not represented on the microarrays. Oligonucleotides were suspended in $3 \times$ SSC (Ambion) at a final concentration of $40 \mu \mathrm{M}$ prior to robotic arraying in quadruplicates onto ultraGAPS coated glass slides (Corning) using a spotarray 72 microarray printer (Perkin Elmer). Printed slides were steamed, UV cross-linked and stored in desiccators until use.

\section{Probe labeling and microarray slide hybridization}

The RNAs were converted to cDNA and labeled with Cy3 fluorescent dyes (Amersham Biosciences), using a two-step protocol as previously described [74,75]. Briefly, total RNA $(30 \mu \mathrm{g})$ was first converted to cDNAs with incorporation of a chemically reactive nucleotide analog (amino allyl-dUTP) using Superscript III reverse transcriptase and random hexamers (Invitrogen). This cDNA is then "post labeled" with the reactive forms of fluoroLink Cy3-NHS esters (Amersham), which bind to the modified nucleotides. The labeled cDNAs were then combined with $0.5 \mu \mathrm{g}$ of labeled gDNA to a final volume of $35 \mu \mathrm{L}$. Samples were heated at $95^{\circ} \mathrm{C}$ for $5 \mathrm{~min}$ and then kept at $45^{\circ} \mathrm{C}$ until hybridization, when $35 \mu \mathrm{L}$ of $2 \times$ formamide-based hybridization buffer $(50 \%$ formamide; $10 \times$ SSC; $0.2 \%$ SDS) were added to each sample. Samples were then well-mixed and applied to custom $3.2 \mathrm{~K}$ Brucella oligo-arrays. Prior to hybridization, oligo-arrays were pretreated by washing in $0.2 \%$ SDS, followed by 3 washes in distilled water, and immersed in prehybridization buffer $(5 \times \mathrm{SSC}, 0.1 \%$ SDS; $1 \%$ BSA in $100 \mathrm{ml}$ of water) at $45^{\circ} \mathrm{C}$ for at least $45 \mathrm{~min}$. Immediately before hybridization, the slides were washed $4 \times$ in distilled water, dipped in $100 \%$ isopropanol for $10 \mathrm{sec}$ and dried by centrifugation at $1,000 \times g$ for $2 \mathrm{~min}$.

Four slides for each condition (i.e. B. suis 1330 wild-type and the $\Delta r s h$ mutant) were hybridized at $45^{\circ} \mathrm{C}$ for $\sim 20 \mathrm{~h}$ in a dark, humid chamber (Corning) and then washed for $10 \mathrm{~min}$ at $45^{\circ} \mathrm{C}$ with low stringency buffer $(1 \times$ SSC, $0.2 \%$ SDS), followed by two 5 -min washes in a higher stringency buffer $(0.1 \times \mathrm{SSC}, 0.2 \%$ SDS and $0.1 \times \mathrm{SSC})$ at room temperature with agitation. Slides were dried by centrifugation at $800 \times g$ for $2 \mathrm{~min}$ and immediately scanned. 


\section{Data acquisition and microarray data analysis}

Hybridized microarrays were scanned using a GenePix 4000A dual-channel (635 $\mathrm{nm}$ and $532 \mathrm{~nm}$ ) confocal laser scanner (Axon Instruments). The genes represented on the arrays were adjusted for background and normalized to internal controls using image analysis software (GenePixPro 4.0; Axon Instruments Inc.). Genes with fluorescent signal values below background were disregarded in all analyses. Statistical analysis was performed by Seralogix, LLC, Austin, TX, employing their computational tools termed the BioSignature Discovery System (BioSignatureDS) to determine significant gene modulations via a Bayesian $z$-score sliding window threshold technique and fold change. Normalizations against genomic DNA were performed as previously described [69]. The microarray data were deposited in the Gene Expression Omnibus (GEO) database at the National Center for Biotechnology Information (Accession \#: GSE44688), including the ortholog gene references of B. suis attributed to the spot-IDs of the microarrays. For determination of significant differential gene expression, an absolute value for $\mathrm{z}$-score cut-off of $+/-1.96$ was employed, which is equivalent to $95 \%$ confidence for the two-sided $t$-test with all genes differentially expressed having a plain fold change greater than the absolute value of 1.5. More detailed description of the computational techniques employed by BioSignatureDS was described in previous publications [76,77].

\section{RT-qPCR analysis}

Expression of randomly selected genes from most of the different functional categories $(n=19)$ that we defined based on microarray analysis, and which were differentially expressed between $B$. suis wild-type and the $r s h$ mutant, was analyzed by quantitative RT-PCR (RT-qPCR). $800 \mathrm{ng}$ from the same RNA samples used for microarray hybridization were reverse-transcribed using a 6-mer random primers mix, as described earlier [75], and quantitative RT-PCR experiments were performed using the Light Cycler 480 with SYBR green chemistry to monitor and quantify the amplification rate (Roche). Primers (Sigma Genosys) were designed using Primer 3 Software (Additional file 3: Table S2) to produce an amplicon length between 150 and $250 \mathrm{bp}$. For each gene tested, the mean calculated threshold cycles $(\mathrm{Ct})$ of the wild-type and the mutant were averaged and normalized to the $\mathrm{Ct}$ of a gene with constant expression identified in the transcriptomic analysis. The normalized $\mathrm{Ct}$ was used for calculating the fold change using the $\Delta \Delta C_{t}$ method [78]. Briefly, relative fold change ( $\Delta r s h$ mutant/ wild-type $)=2^{-\Delta \Delta \mathrm{Ct}}$, where $\Delta \mathrm{Ct}$ (Gene of interest $)=\mathrm{Ct}$ (Gene of interest)-Ct (Reference gene of the same sample, BR1035) and $\Delta \Delta \mathrm{Ct}$ (Gene of interest) $=\Delta \mathrm{Ct}(\Delta r s h$ mutant)- $\Delta \mathrm{Ct}$ (wild-type). BR1035, characterized by constant expression in both strains in minimal medium, was used as reference gene. For each primer pair, a negative control (water) and a RNA sample without reverse transcriptase (to determine genomic DNA contamination) were included as controls during cDNA quantification. Array data were considered valid if the fold change of each gene tested by RT-qPCR was log2 $(x)>0.66$ or $\log 2(1 / x)<-0.66$ (representing a plain foldchange $>1.5$ ) and consistent with microarray analysis.

\section{Nitrate reductase assay}

To assess the amount of nitrite produced, the culture supernatants were assayed for nitrite accumulation by a spectrophotometric assay based on the Griess reaction [44]. B. suis wild-type and $\Delta r s h$ were washed in PBS, and incubated in GMM pH 7.0 containing $10 \mathrm{mM}$ of $\mathrm{NaNO}_{3}$ for $6 \mathrm{~h}$ at $37^{\circ} \mathrm{C}$ under vigorous shaking for aeration. The nitrite concentration was measured with $100 \mu \mathrm{l}$ of pure or diluted culture supernatants in $100 \mu \mathrm{l}$ of Griess reagent containing $1 \%$ sulfamide in $70 \%$ acetic acid, and $0.1 \% \mathrm{~N}$ (naphthyl) ethylenediamine in $60 \%$ acetic acid. A pink color indicated nitrites in the supernatants, and OD was measured at $570 \mathrm{~nm}$. Nitrite concentrations between 0 and $200 \mu \mathrm{M}$ were used for a calibration curve.

\section{Measurement of in vitro sensitivity to superoxide production}

A previously described procedure was used to follow up superoxide dismutase activity [52]. Briefly, mid-log phase cultures of $B$. suis wild-type, the $\Delta r s h$ mutant and the complemented mutant grown in Tryptic Soy broth were washed twice in phosphate-buffered saline (PBS) and adjusted to a density of approximately $10^{6} \mathrm{CFU} / \mathrm{ml}$. Xanthine at the final concentration of $2 \mathrm{mM}$ and $1 \mathrm{U} / \mathrm{ml}$ of xanthine oxidase were added to these cell suspensions along with $1,000 \mathrm{U} / \mathrm{ml}$ of bovine liver catalase to detoxify any $\mathrm{H}_{2} \mathrm{O}_{2}$ generated by spontaneous dismutation of the $\mathrm{O}_{2}^{-}$produced during the xanthine oxydase reaction. At specific time points after initiating the xanthine oxidase reaction, the number of surviving bacteria in the cell suspension was determined by 10 -fold serial dilutions and plating on TS agar. Plates were incubated for 3 days at $37^{\circ} \mathrm{C}$. The means from 3 independent platings of each bacterial cell suspension were calculated, and the data obtained were expressed as $\log 10 \mathrm{CFU} / \mathrm{ml}$ at each sampling time, \pm standard deviations.

\section{Construction of $r$ sh and methionine mutants of $B$. suis}

The $r s h$ null mutant has been described previously [23]. The mutants in methionine biosynthesis genes (met $A$, met $Z$, met $H$ and BR0793) contained a kanamycin resistance gene, replacing an internal portion of the target gene. For this purpose, 1239-, 1484-, 4045-, and 1451-bp fragments of met $A$, met $Z$, met $H$ and BR0793, respectively, 
were amplified by PCR from the genomic DNA of B. suis with specific primers listed in Additional file 3: Table S2 (Sigma Genosys). These PCR fragments were inserted into pGEM-T Easy (Promega). The resulting plasmids were digested by BssHII, BsmI-BamHI, StuI, and BsmI-HindIII, respectively, to delete internal DNA fragments, and treated with T4-DNA-polymerase to obtain blunt-ended extremities. The deleted fragments were replaced by the kanamycin resistance gene excised from plasmid pUC4K using HincII. To generate met mutants, the resulting suicide plasmids were introduced into B. suis by electroporation. $\mathrm{Kan}^{\mathrm{R}} / \mathrm{Amp}^{\mathrm{S}}$ allelic exchange mutants were selected and validated by PCR. For complementation, the metH was excised from pGEM-T and subcloned into the ApaI-SacI sites of pBBR1MCS. The obtained plasmid pBBR1MCS-metH was transformed into $\Delta m e t H_{\mathrm{Bs}}$. Complemented $\Delta m e t H$ mutants were selected on the basis of their $\operatorname{Kan}^{\mathrm{R}}-\mathrm{Cm}^{\mathrm{R}}$ phenotype.

\section{Macrophage infection experiments with Brucella strains} Experiments were performed as described previously [79]. Briefly, murine J774A.1 macrophage-like cells were infected with early-stationary-phase $B$. suis strains for $45 \mathrm{~min}$ at a multiplicity of infection (MOI) of 20 bacteria per cell. Cells were washed twice with PBS and reincubated in RPMI 1640 with 10\% fetal calf serum and gentamicin at $30 \mu \mathrm{g} / \mathrm{ml}$ for at least $1 \mathrm{~h}$ to kill extracellular bacteria. After incubation of macrophages at $37^{\circ} \mathrm{C}$ and $5 \% \mathrm{CO}_{2}$ for various time periods, cells were washed twice with PBS and lysed in $0.2 \%$ Triton X-100. The number of intracellular live bacteria was determined by plating serial dilutions on TS agar plates and incubation at $37^{\circ} \mathrm{C}$ for 3 days. All experiments were performed at least three times in triplicate.

\section{Additional files}

Additional file 1: Table S1. Up-regulation (grey) and down-regulation (white) of Rsh-dependent genes in the B. suis wild-type, as determined by transcriptome analysis of the stringent response, in comparison to the rsh-mutant.

Additional file 2: Figure S1. Comparison of microarray analysis to realtime PCR revealed $78 \%$ of true positives. Fold-change of differentially expressed genes is shown for normalized microarray data and RT-qPCR of 27 ORFs (out of 40 total; see also Figure 2) representing the different functional groups: (A) H- DNA/RNA metabolism; I- Energy metabolism; JFatty acid metabolism; K- Nitrogen metabolism; L- Protein metabolism; NRegulation. (B) O: Stress and adaptation/chaperones/protein folding; P: Sugar metabolism; Q: Transport systems; R: Transposon function; S: Unknown function. Expression of $78 \%$ of all chosen ORFs (see also Figure 2) was consistent for both methods, with a fold-change superior to 1.5 . For the remaining $22 \%$, the fold-change was inferior to 1.5 or no consistent with microarray analysis. Relative differences of transcription levels between $B$. suis wild-type and the $\Delta r$ sh mutant were determined as $2^{-\Delta \Delta C t}$ values, as described in Methods.

Additional file 3: Table S2. Oligonucleotides used in this study.

\section{Competing interests}

$\mathrm{KD}$ is an employee of Seralogix, LLC, and has an equity position in this company. Seralogix, LLC is a private business developing the software analysis and modeling software for commercial purposes which was utilized in the analysis of the data in this article.

The other authors declare that they have no competing interests.

\section{Authors' contributions}

$\mathrm{NH}, \mathrm{SOB}$, and $\mathrm{AO}$ carried out the experiments. $\mathrm{NH}, \mathrm{AO}$ and $\mathrm{SK}$ conceived the study and contributed to the interpretation of the data. GA and KD

developed the microarrays and performed and contributed to the microarray data normalization and processing. $\mathrm{NH}, \mathrm{SOB}, \mathrm{AO}$ and SK were involved in

drafting the manuscript. All authors read and approved the final manuscript.

\section{Acknowledgements}

The study was supported by funds from the Centre National de la Recherche Scientifique (CNRS). N. Hanna was supported by a fellowship from the Lebanese CNRS. We thank V. Jubier-Maurin for critical reading and helpful comments on the manuscript. We acknowledge P. Bouhours for the preparation of bacterial media, E. Hauser and M. Korrichi for helpful technical assistance, and P. Clair (qPCR Platform, UMS Biocampus, University of Montpellier 2) for assistance in RNA analysis and RT-qPCR. We are grateful to the United States Department of Health and Human Services, National Institutes of Health (NIH), Western Regional Center of Excellence (WRCE) Pathogen Expression Core (Drs. M. McGee, R. Friedberg and S. A. Johnston, Arizona State University, Tempe, AZ) for developing and printing the B. melitensis CDNA microarrays supported by NIH award 2U54AI057156-06 and the United States Department of Homeland Security (DHS), National Center of Excellence for Foreign Animal and Zoonotic Disease (FAZD) Defense award ONR-N00014-04-1-0.

\section{Author details}

'Université Montpellier 1, Centre d'études d'agents Pathogènes et Biotechnologies pour la Santé (CPBS), Montpellier, France. ${ }^{2}$ CNRS, UMR 5236, CPBS, Montpellier, France. ${ }^{3}$ Université Montpellier 2, CPBS, Montpellier, France. ${ }^{4}$ Seralogix, Limited Liability Company, Austin, TX, USA. ${ }^{5}$ Department of Veterinary Pathobiology, College of Veterinary Medicine and Biomedical Sciences, Texas A\&M University, College Station, TX, USA.

Received: 27 March 2013 Accepted: 18 June 2013

Published: 8 July 2013

\section{References}

1. Franco MP, Mulder M, Gilman $\mathrm{RH}$, Smits $\mathrm{HL}$ : Human brucellosis. Lancet Infect Dis 2007, 7:775-786.

2. Celli J, de Chastellier C, Franchini DM, Pizarro-Cerda J, Moreno E, Gorvel JP: Brucella evades macrophage killing via VirB-dependent sustained interactions with the endoplasmic reticulum. J Exp Med 2003, 198:545-556.

3. O'Callaghan D, Cazevieille C, Allardet-Servent A, Boschiroli ML, Bourg G, Foulongne $V$, Frutos $P$, Kulakov $Y$, Ramuz M: A homologue of the Agrobacterium tumefaciens VirB and Bordetella pertussis Ptl type IV secretion systems is essential for intracellular survival of Brucella suis. Mol Microbiol 1999, 33:1210-1220.

4. Cashel M, Gallant J: Two compounds implicated in the function of the RC gene of Escherichia coli. Nature 1969, 221:838-841.

5. Toulokhonov I, Artsimovitch I, Landick R: Allosteric control of RNA polymerase by a site that contacts nascent RNA hairpins. Science 2001, 292:730-733.

6. Murray KD, Bremer $\mathrm{H}$ : Control of spoT-dependent ppGpp synthesis and degradation in Escherichia coli. J Mol Biol 1996, 259:41-57.

7. Traxler MF, Summers SM, Nguyen HT, Zacharia VM, Hightower GA, Smith JT, Conway T: The global, ppGpp-mediated stringent response to amino acid starvation in Escherichia coli. Mol Microbiol 2008, 68:1128-1148.

8. Xiao H, Kalman M, Ikehara K, Zemel S, Glaser G, Cashel M: Residual guanosine 3',5'-bispyrophosphate synthetic activity of relA null mutants can be eliminated by spoT null mutations. J Bio/ Chem 1991, 266:5980-5990.

9. Boutte CC, Crosson S: The complex logic of stringent response regulation in Caulobacter crescentus: starvation signalling in an oligotrophic environment. Mol Microbio/ 2011, 80:695-714. 
10. Krol E, Becker A: ppGpp in Sinorhizobium meliloti: biosynthesis in response to sudden nutritional downshifts and modulation of the transcriptome. Mol Microbiol 2011, 81:1233-1254.

11. Vinella D, Albrecht C, Cashel M, D'Ari R: Iron limitation induces SpoT-dependent accumulation of ppGpp in Escherichia coli. Mol Microbiol 2005, 56:958-970.

12. Potrykus K, Cashel M: (p) ppGpp: Still Magical?*. Annu Rev Microbiol 2008, 62:35-51.

13. Mittenhuber $\mathrm{G}$ : Comparative genomics and evolution of genes encoding bacterial (p)ppGpp synthetases/hydrolases (the Rel, RelA and SpoT proteins). J Mol Microbiol Biotechnol 2001, 3:585-600.

14. Hogg T, Mechold U, Malke H, Cashel M, Hilgenfeld R: Conformational antagonism between opposing active sites in a bifunctional RelA/SpoT homolog modulates (p) ppGpp metabolism during the stringent response. Cell 2004, 117:57-68.

15. Vercruysse M, Fauvart M, Jans A, Beullens S, Braeken K, Cloots L, Engelen K, Marchal K, Michiels J: Stress response regulators identified through genome-wide transcriptome analysis of the (p)ppGpp-dependent response in Rhizobium etli. Genome Biol 2011, 12:R17.

16. Kazmierczak KM, Wayne KJ, Rechtsteiner A, Winkler ME: Roles of rel(Spn) in stringent response, global regulation and virulence of serotype 2 Streptococcus pneumoniae D39. Mol Microbiol 2009, 72:590-611.

17. Dalebroux ZD, Edwards RL, Swanson MS: SpoT governs Legionella pneumophila differentiation in host macrophages. Mol Microbiol 2009, 71:640-658.

18. Primm TP, Andersen SJ, Mizrahi V, Avarbock D, Rubin H, Barry CE 3rd: The stringent response of Mycobacterium tuberculosis is required for long-term survival. J Bacteriol 2000, 182:4889-4898.

19. Dahl JL, Kraus CN, Boshoff HI, Doan B, Foley K, Avarbock D, Kaplan G, Mizrahi $V$, Rubin H, Barry CE 3rd: The role of RelMtb-mediated adaptation to stationary phase in long-term persistence of Mycobacterium tuberculosis in mice. Proc Natl Acad Sci USA 2003, 100:10026-10031.

20. Nguyen D, Joshi-Datar A, Lepine F, Bauerle E, Olakanmi O, Beer K, McKay G, Siehnel R, Schafhauser J, Wang $Y$, et al: Active starvation responses mediate antibiotic tolerance in biofilms and nutrient-limited bacteria. Science 2011, 334:982-986.

21. Wells DH, Long SR: The Sinorhizobium meliloti stringent response affects multiple aspects of symbiosis. Mol Microbiol 2002, 43:1115-1127.

22. Köhler S, Foulongne V, Ouahrani-Bettache S, Bourg G, Teyssier J, Ramuz M, Liautard JP: The analysis of the intramacrophagic virulome of Brucella suis deciphers the environment encountered by the pathogen inside the macrophage host cell. Proc Natl Acad Sci USA 2002, 99:15711-15716.

23. Dozot M, Boigegrain RA, Delrue RM, Hallez R, Ouahrani-Bettache S, Danese I, Letesson JJ, De Bolle X, Köhler S: The stringent response mediator Rsh is required for Brucella melitensis and Brucella suis virulence, and for expression of the type IV secretion system virB. Cell Microbiol 2006, 8:1791-1802.

24. Kim S, Watanabe K, Suzuki H, Watarai M: Roles of Brucella abortus SpoT in morphological differentiation and intramacrophagic replication. Microbiology 2005, 151:1607-1617.

25. Sieira R, Comerci DJ, Pietrasanta LI, Ugalde RA: Integration host factor is involved in transcriptional regulation of the Brucella abortus virB operon. Mol Microbiol 2004, 54:808-822.

26. Loisel-Meyer S, Jiménez de Bagüés MP, Köhler S, Liautard JP, Jubier-Maurin $\checkmark$ : Differential use of the two high-oxygen-affinity terminal oxidases of Brucella suis for in vitro and intramacrophagic multiplication. Infect Immun 2005, 73:7768-7771.

27. Jiménez de Bagüés MP, Loisel-Meyer S, Liautard JP, Jubier-Maurin V: Different roles of the two high-oxygen-affinity terminal oxidases of Brucella suis: Cytochrome c oxidase, but not ubiquinol oxidase, is required for persistence in mice. Infect Immun 2007, 75:531-535.

28. Rindi L, Bonanni D, Lari N, Garzelli C: Requirement of gene fadD33 for the growth of Mycobacterium tuberculosis in a hepatocyte cell line. New Microbiol 2004, 27:125-131.

29. Dunphy KY, Senaratne RH, Masuzawa M, Kendall LV, Riley LW: Attenuation of Mycobacterium tuberculosis functionally disrupted in a fatty acyl-coenzyme A synthetase gene fadD5. J Infect Dis 2010, 201:1232-1239.

30. Lynett J, Stokes RW: Selection of transposon mutants of Mycobacterium tuberculosis with increased macrophage infectivity identifies fadD23 to be involved in sulfolipid production and association with macrophages. Microbiology 2007, 153:3133-3140.
31. Fee JA: Regulation of sod genes in Escherichia coli: relevance to superoxide dismutase function. Mol Microbiol 1991, 5:2599-2610.

32. Bigot S, Sivanathan V, Possoz C, Barre FX, Cornet F: FtsK, a literate chromosome segregation machine. Mol Microbiol 2007, 64:1434-1441.

33. Valderas MW, Alcantara RB, Baumgartner JE, Bellaire BH, Robertson GT, Ng WL, Richardson JM, Winkler ME, Roop RM II: Role of HdeA in acid resistance and virulence in Brucella abortus 2308. Vet Microbiol 2005 107:307-312.

34. Sieira R, Arocena GM, Bukata L, Comerci DJ, Ugalde RA: Metabolic control of virulence genes in Brucella abortus: HutC coordinates virB expression and the histidine utilization pathway by direct binding to both promoters. J Bacteriol 2010, 192:217-224.

35. Wu Q, Pei J, Turse C, Ficht TA: Mariner mutagenesis of Brucella melitensis reveals genes with previously uncharacterized roles in virulence and survival. BMC Microbiol 2006, 6:102

36. Caswell CC, Elhassanny AE, Planchin EE, Roux CM, Weeks-Gorospe JN, Ficht TA, Dunman PM, Roop RM II: The diverse genetic regulon of the virulence-associated transcriptional regulator MucR in Brucella abortus 2308. Infect Immun 2013: . e-pub ahead of print, Jan 14

37. Mirabella A, Terwagne M, Zygmunt MS, Cloeckaert A, De Bolle X, Letesson $\mathrm{JJ}$ : Brucella melitensis MucR, an orthologue of Sinorhizobium meliloti MucR, is involved in resistance to oxidative, detergent and saline stresses and cell envelope modifications. J Bacteriol 2013, 195:453-465.

38. Bahlawane C, McIntosh M, Krol E, Becker A: Sinorhizobium meliloti regulator MucR couples exopolysaccharide synthesis and motility. $\mathrm{Mol}$ Plant Microbe Interact 2008, 21:1498-1509.

39. Mueller K, Gonzalez JE: Complex regulation of symbiotic functions is coordinated by MucR and quorum sensing in Sinorhizobium meliloti. J Bacteriol 2011, 193:485-496.

40. Aberg A, Shingler $V$, Balsalobre $C$ : (p)ppGpp regulates type 1 fimbriation of Escherichia coli by modulating the expression of the site-specific recombinase FimB. Mol Microbiol 2006, 60:1520-1533.

41. Anderson KL, Roberts C, Disz T, Vonstein V, Hwang K, Overbeek R, Olson PD, Projan SJ, Dunman PM: Characterization of the Staphylococcus aureus heat shock, cold shock, stringent, and SOS responses and their effects on log-phase mRNA turnover. J Bacteriol 2006, 188:6739.

42. Delrue RM, Lestrate P, Tibor A, Letesson JJ, De Bolle X: Brucella pathogenesis, genes identified from random large-scale screens. FEMS Microbiol Lett 2004, 231:1-12.

43. Fretin D, Fauconnier A, Köhler S, Halling S, Leonard S, Nijskens C, Ferooz J, Lestrate P, Delrue RM, Danese I, et al: The sheathed flagellum of Brucella melitensis is involved in persistence in a murine model of infection. Cell Microbiol 2005, 7:687-698.

44. Loisel-Meyer $\mathrm{S}$, Jiménez de Bagüés MP, Basseres E, Dornand J, Köhler S, Liautard JP, Jubier-Maurin V: Requirement of norD for Brucella suis virulence in a murine model of in vitro and in vivo infection. Infect Immun 2006, 74:1973-1976.

45. Boschiroli ML, Ouahrani-Bettache S, Foulongne V, Michaux-Charachon S, Bourg G, Allardet-Servent A, Cazevieille C, Liautard JP, Ramuz M, O'Callaghan $D$ : The Brucella suis virB operon is induced intracellularly in macrophages. Proc Natl Acad Sci USA 2002, 99:1544-1549.

46. Ali Azam T, Iwata A, Nishimura A, Ueda S, Ishihama A: Growth phasedependent variation in protein composition of the Escherichia coli nucleoid. J Bacterio/ 1999, 181:6361-6370.

47. Aviv M, Giladi H, Schreiber G, Oppenheim AB, Glaser G: Expression of the genes coding for the Escherichia coli integration host factor are controlled by growth phase, rpoS, ppGpp and by autoregulation. Mol Microbiol 1994, 14:1021-1031.

48. Rambow-Larsen AA, Petersen EM, Gourley CR, Splitter GA: Brucella regulators: self-control in a hostile environment. Trends Microbiol 2009, 17:371-377.

49. Arenas-Gamboa AM, Rice-Ficht AC, Kahl-McDonagh MM, Ficht TA: Protective efficacy and safety of Brucella melitensis 16MDeltamucR against intraperitoneal and aerosol challenge in BALB/C mice. Infect Immun 2011, 79:3653-3658.

50. Occhialini A, Jiménez de Bagüés MP, Saadeh B, Bastianelli D, Hanna N, De Biase D, Köhler S: The glutamic acid decarboxylase system of the new species Brucella microti contributes to its acid resistance and to oral infection of mice. J Infect Dis 2012, 206:1424-1432.

51. Gee JM, Kovach ME, Grippe VK, Hagius S, Walker JV, Elzer PH, Roop RM II: Role of catalase in the virulence of Brucella melitensis in pregnant goats. Vet Microbiol 2004, 102:111-115. 
52. Gee JM, Valderas MW, Kovach ME, Grippe VK, Robertson GT, Ng WL, Richardson JM, Winkler ME, Roop RM II: The Brucella abortus Cu, Zn superoxide dismutase is required for optimal resistance to oxidative killing by murine macrophages and wild-type virulence in experimentally infected mice. Infect Immun 2005, 73:2873-2880.

53. Durfee $T$, Hansen AM, Zhi H, Blattner FR, Jin DJ: Transcription profiling of the stringent response in Escherichia coli. J Bacteriol 2008, 190:1084-1096.

54. Cashel M, Gentry DR, Hernandez VJ, Vinella D: The stringent response. In Escherichia coli and Salmonella: cellular and molecular biology. 2nd edition. Edited by Neidhardt FC, Curtiss R III, Ingraham JL, Lin ECC, Low KB, Magasanik B, Reznikoff WS, Riley M, Schaechter M, Umbarger HE. Washington, D.C: ASM Press; 1996:1458-1496.

55. Eymann C, Homuth G, Scharf C, Hecker M: Bacillus subtilis functional genomics: global characterization of the stringent response by proteome and transcriptome analysis. J Bacterio/ 2002, 184:2500-2520.

56. Kim S, Watarai M, Suzuki H, Makino S, Kodama T, Shirahata T: Lipid raft microdomains mediate class A scavenger receptor-dependent infection of Brucella abortus. Microb Pathog 2004, 37:11-19.

57. Lestrate P, Delrue RM, Danese I, Didembourg C, Taminiau B, Mertens P, De Bolle X, Tibor A, Tang CM, Letesson JJ: Identification and characterization of in vivo attenuated mutants of Brucella melitensis. Mol Microbiol 2000, 38:543-551

58. DelVecchio VG, Kapatral V, Redkar RJ, Patra G, Mujer C, Los T, Ivanova N, Anderson I, Bhattacharyya A, Lykidis A, et al: The genome sequence of the facultative intracellular pathogen Brucella melitensis. Proc Natl Acad Sci USA 2002, 99:443-448.

59. Zumft WG: Cell biology and molecular basis of denitrification. Microbiol Mol Biol Rev 1997, 61:533-616.

60. Haine V, Dozot M, Dornand J, Letesson JJ, De Bolle X: NnrA is required for full virulence and regulates several Brucella melitensis denitrification genes. J Bacteriol 2006, 188:1615-1619.

61. Al Dahouk S, Loisel-Meyer S, Scholz HC, Tomaso H, Kersten M, Harder A, Neubauer H, Köhler S, Jubier-Maurin V: Proteomic analysis of Brucella suis under oxygen deficiency reveals flexibility in adaptive expression of various pathways. Proteomics 2009, 9:3011-3021.

62. Showe MK, DeMoss JA: Localization and regulation of synthesis of nitrate reductase in Escherichia coli. J Bacteriol 1968, 95:1305-1313.

63. Clegg S, Yu F, Griffiths L, Cole JA: The roles of the polytopic membrane proteins NarK, NarU and NirC in Escherichia coli K-12: two nitrate and three nitrite transporters. Mol Microbiol 2002, 44:143-155.

64. Sohaskey CD, Wayne LG: Role of narK2X and narGHJI in hypoxic upregulation of nitrate reduction by Mycobacterium tuberculosis. J Bacteriol 2003, 185:7247-7256.

65. Bandara AB, Contreras A, Contreras-Rodriguez A, Martins AM, Dobrean V, Poff-Reichow S, Rajasekaran P, Sriranganathan N, Schurig GG, Boyle SM: Brucella suis urease encoded by ure 1 but not ure2 is necessary for intestinal infection of BALB/c mice. BMC Microbio/ 2007, 7:57.

66. Sangari FJ, Seoane A, Rodriguez MC, Aguero J, Garcia Lobo JM: Characterization of the urease operon of Brucella abortus and assessment of its role in virulence of the bacterium. Infect Immun 2007, 75:774-780

67. Brockmann-Gretza O, Kalinowski J: Global gene expression during stringent response in Corynebacterium glutamicum in presence and absence of the rel gene encoding (p)ppGpp synthase. BMC Genomics 2006, 7:230

68. Sangari FJ, Cayon AM, Seoane A, Garcia-Lobo JM: Brucella abortus ure2 region contains an acid-activated urea transporter and a nickel transport system. BMC Microbiol 2010, 10:107.

69. Rossetti CA, Galindo CL, Lawhon SD, Garner HR, Adams LG: Brucella melitensis global gene expression study provides novel information on growth phase-specific gene regulation with potential insights for understanding Brucella:host initial interactions. BMC Microbiol 2009, 9:81.

70. Lemke JJ, Durfee T, Gourse RL: DksA and ppGpp directly regulate transcription of the Escherichia coli flagellar cascade. Mol Microbiol 2009, 74:1368-1379

71. Al Dahouk S, Jubier-Maurin V, Scholz HC, Tomaso H, Karges W, Neubauer H, Köhler S: Quantitative analysis of the intramacrophagic Brucella suis proteome reveals metabolic adaptation to late stage of cellular infection. Proteomics 2008, 8:3862-3870.

72. Kim HS, Caswell CC, Foreman R, Roop RM II, Crosson S: The Brucella abortus General Stress Response System Regulates Chronic Mammalian
Infection and Is Controlled by Phosphorylation and Proteolysis. J Biol Chem 2013, 288:13906-13916.

73. Lestrate P, Dricot A, Delrue RM, Lambert C, Martinelli V, De Bolle X, Letesson $J$ J, Tibor A: Attenuated signature-tagged mutagenesis mutants of Brucella melitensis identified during the acute phase of infection in mice. Infect Immun 2003, 71:7053-7060.

74. Hegde P, Qi R, Abernathy K, Gay C, Dharap S, Gaspard R, Hughes JE, Snesrud E, Lee N, Quackenbush J: A concise guide to cDNA microarray analysis. Biotechniques 2000, 29:548-550. 552-544, 556 passim.

75. Occhialini A, Cunnac S, Reymond N, Genin S, Boucher C: Genome-wide analysis of gene expression in Ralstonia solanacearum reveals that the hrpB gene acts as a regulatory switch controlling multiple virulence pathways. Mol Plant Microbe Interact 2005, 18:938-949.

76. Lawhon SD, Khare S, Rossetti CA, Everts RE, Galindo CL, Luciano SA, Figueiredo JF, Nunes JE, Gull T, Davidson GS, et al: Role of SPI-1 secreted effectors in acute bovine response to Salmonella enterica Serovar Typhimurium: a systems biology analysis approach. PLoS One 2011, 6:e26869.

77. Khare S, Lawhon SD, Drake KL, Nunes JE, Figueiredo JF, Rossetti CA, Gull T, Everts RE, Lewin HA, Galindo CL, et al: Systems biology analysis of gene expression during in vivo Mycobacterium avium paratuberculosis enteric colonization reveals role for immune tolerance. PLoS One 2012, 7:e42127.

78. Hanna N, Jiménez de Bagüés MP, Ouahrani-Bettache S, El Yakhlifi Z, Köhler $S$, Occhialini A: The virB operon is essential for lethality of Brucella microti in the Balb/c murine model of infection. J Infect Dis 2011, 203:1129-1135.

79. Jiménez de Bagüés MP, Ouahrani-Bettache S, Quintana JF, Mitjana O, Hanna N, Bessoles S, Sanchez F, Scholz HC, Lafont V, Köhler S, et al: The new species Brucella microti replicates in macrophages and causes death in murine models of infection. J Infect Dis 2010, 202:3-10.

doi:10.1186/1471-2164-14-459

Cite this article as: Hanna et al:: Global Rsh-dependent transcription profile of Brucella suis during stringent response unravels adaptation to nutrient starvation and cross-talk with other stress responses. BMC Genomics 2013 14:459.

\section{Submit your next manuscript to BioMed Central and take full advantage of:}

- Convenient online submission

- Thorough peer review

- No space constraints or color figure charges

- Immediate publication on acceptance

- Inclusion in PubMed, CAS, Scopus and Google Scholar

- Research which is freely available for redistribution

Submit your manuscript at www.biomedcentral.com/submit
C Biomed Central 